\title{
Perancangan Sistem Informasi Jasa Katering Berbasis Website
}

\author{
Supriyanta ${ }^{1)}$, Idzni Masturah ${ }^{2)}$ \\ Universitas Bina Sarana Informatika \\ 1) supriyanta.spt@bsi.ac.id \\ 2)idznimasturah42@gmail.com
}

\begin{abstract}
In this modern age the development of technology greatly influences human life in all fields, one of which is in the catering business. Technology makes everything more practical and easy. Business people use technology as a means to develop their business. Catering entrepreneurs, for example, can use technology to deliver information about their catering business and customers can order online. The design of this information system is made using HTML programming languages and PHP MySQL. The method of data collection uses the method of observation and literature, the method of designing the system with a waterfall and in its testing using black box testing. The application of the catering website is expected to facilitate customers in catering reservations and can increase the profits of catering entrepreneurs.
\end{abstract}

Keywords: Catering, Mockery, Waterfall

ABSTRAKSI: Di zaman modern ini perkembangan teknologi sangat mempengaruhi kehidupan manusia dalam segala bidang, salah satunya dalam bisnis katering. Teknologi membuat segalanya menjadi lebih praktis dan mudah. Para pebisnis menggunakan teknologi sebagai sarana untuk mengembangkan usahanya. Pengusaha katering misalnya, bisa memanfaatkan teknologi untuk menyampaikan informasi bisnisnya kateringnya dan pelanggan bisa melakukan pemesanan secara online. Perancangan sistem informasi ini dibuat dengan menggunakan bahasa pemprograman HTML dan PHP MySQL. Metode pengumpulan data memakai cara observasi dan studi pustaka, metode perancangan sistem dengan waterfall dan dalam pengujiannya menggunakan pengujian kotak hitam. Aplikasi situs web katering ini diharapkan dapat mempermudah pelanggan dalam pemesanan katering dan dapat meningkatkan keuntungan pengusaha katering.

Kata Kunci : Perangcangan, Katering, Waterfall

\section{1.a. Latar Belakang}

Kemajuan teknologi sangat mempengaruhi kehidupan manusia dalam segala bidang, salah satunya adalah dalam bidang bisnis. Tuntutan manusia yang selalu ingin mendapatkan pelayanan yang cepat dan tepat, mudah dan praktis terjawab dengan adanya teknologi. Banyak pengusaha yang berusaha menerapkan teknologi dalam hal ini teknologi informasi untuk membantu bisnisnya.

Pengembangan bisnis di bidang katering yang melayani penjualan produk makanan pun dapat memanfaatkan teknologi informasi agar bisa bersaing dan bisa maju. Usaha katering yang konvensional dimana hanya menjual produk di sekitar lokasi usaha, di daerah yang lingkupnya terbatas, dengan promosi dari mulut ke mulut, dengan pelayanan yang tradisional jelas akan sulit untuk berkembang. Perlu inovasi dengan memakai teknologi agar bisnis katering bisa maju.

\section{1.b. Rumusan Masalah}

1. Bagaimana caranya agar dapat menggunakan teknologi informasi berbasis website untuk meningkatkan pengembangan bisnis?

2. Apakah bisnis katering bisa dikembangkan dengan menggunakan sistem online?

\section{1.c. Batasan Masalah}

Membuat sistem informasi berbasis website untuk meningkatkan penyebaran informasi/ promosi dan mengolah data transaksi katering sehingga mampu meningkatkan/ mengembangkan usaha.

\section{1.d. Tujuan Penelitian}

1. Membantu membuat sebuah sistem informasi untuk melayani katering berbasis website.

2. Mempermudah proses transaksi pemesanan katering dengan website.

3. Membantu menghemat waktu pemesanan agar lebih efektif secara online

4. Membantu memperluas promosi dan jangkauan pemesanan dan kemudahan akses melalui internet

\section{1.e. Manfaat Penelitian} 1. Menghasilkan sistem informasi
berbasis web untuk membantu 
peningkatan usaha katering sehingga meningkatkan omset katering.

2. Pemilik dapat memajukan usaha katering, pengguna jasa katering bisa mendapatkan pelayanan yang menyenangkan.

\section{2.a. Dasar Teori}

Berbagai teori yang mendukung dalam penulisan ini antara lain:

1. INTERNET

"Internet (Interconnected Network) adalah jaringan komputer yang menghubungkan antar jaringan secara global, internet dapat juga disebut jaringan dalam suatu jaringan yang luas" Sibero (2013:10)

"Internet adalah rangkaian hubungan jaringan komputer yang dapat diakses secara umum diseluruh dunia, yang mengirimkan data dalam bentuk paket data berdasarkan standart Internet Protocol (IP)" Yuhefizar dalam Kusniawan dan Sardiarinto (2016:2)

2. WEB

"Web adalah sebuah sistem dengan informasi yang disajikan dalam bentuk teks, gambar, suara, dan lain-lain yang tersimpan dalam sebuah server Web Internet yang disajikan dalam bentuk hiperteks" Simarmata dalam Pradiatiningtyas dan Suparwanto (2017:2)

3. WEB SERVER

"Web Server adalah potongan perangkat lunak yang mendukung berbagai protokol Web, seperti HTTP, HTTPS, dan lain-lain untuk memproses permintaan client". Simarmata dalam Supriyanta dan Nisa (2015:36)

"Web Server adalah sistem komputer dan software yang menyimpan serta mendistribusikan data ke komputer lain lewat internet yang meminta informasi tersebut". Hastanti dkk (2015:3)

4. PROGRAMMING LANGUAGE

merupakan suatu sintak untuk mendefinisikan program komputer, bahasa ini membantu programmer untuk membuat suatu program aplikasi." Dipraja (2014:26)

5. PHP

"PHP atau Hypertext Prepocessor merupakan bahasa pemrogaman berbasis web yang memilik kemampuan dalam memproses data dinamis, yang artinya dapat membentuk suatu tampilan berdasarkan permintaan. PHP merupakan teknologi open source yang bebas diperoleh dan dapat diatur sesusai kebutuhan perusahaan yang didukung oleh komunitas penguna dan pengembanya, web server dibutuhkan untuk menjalankan PHP" Wahyono dalam Ferdika (2017:177)

6. CSS

"Cascading Style Sheet (CSS) adalah skrip yang ditujukan secara khusus untuk mengatur tampilan aplikasi web". Kadir dalam Supriyanta dan Nisa (2015:36)

7. DATABASE

"Database atau basis data adalah kumpulan dari data-data yang memiliki hubungan antara satu data dengan data yang lain dalam suatu organisasi atau perusahaan yang diorganisisr dan dikelola menggunakan perangkat komputer sehingga dapat mempermudah dalam penyediaan informasi dan pengelolaan data itu sendiri bagi yang memerlukan". Andriani (2016:1)

"Database merupakan suatu tempat untuk menyimpan data yang sejenisnya beraneka ragam. Keuntungan menyimpan data di database adalah kemudahan dalam penyimpanan dan menampilkan data karena dalam bentuk tabel". Winarno dan Zaki (2014:102)

8. XAMP

"XAMPP merupakan programpaket PHP dan MySQL berbasis opensource yang saat ini merupakan andalan para programmer PHP dalam melakukan programming dan melakukantesting hasil programnya". Yudhanto dan Agus dalam Supriyanta dan Nisa (2015:36)

"Xampp adalah program yang berisi paket Apache, MySQL, dan phpMyAdmin". Sadeli (2013:4)

9. PHP MYADMIN

"PHP Myadmin adalah sebuah software berbasis pemrograman PHP yang dipergunakan sebagai administrator MySQL melalui browser (web) yang digunakan untuk management database". Rahman dalam Supriyanta dan Nisa (2015:37)

10.NAVIGASI

"Setiap rencana akan dibuat desainnya dan kemudian diproduksi menjadi produk jadi yang bersifat sementara. Pada tahap ini mencakup perencanaan struktur navigasi yang baik untuk antarmuka penggunanya". Binanto dalam Ningrum dan Kholil (2015:3)

11.ERD

Entity Relation Diagram digunakan untuk menggambarkan struktur logical database dalam bentuk diagram ERD, serta menyediakan cara yang sederhana dan mudah untuk memahami bagian berbagai komponen dalam desain database. Connoly dan Begg dalam Purwati dan Hasan (2016:40) 
12.LRS

"Logical Record Structure (LRS) adalah representasi dari struktur record-record pada tabel-tabel yang terbentuk dari hasil relasi antar himpunan entitas". Simamarta dan Paryudi dalam Fridayanthie dan Mahdiati (2016:132)

\section{BLACK BOX TESTING}

"Pada Black BoxTesting, cara pengujian hanya dilakukan dengan menjalankan atau mengeksekusi unit atau modul, kemudian diamati apakah hasil dari unit itu sesuai dengan proses bisnis yang diinginkan". Menurut Fatta dalam Wibisono dan Susanto (2015:67)

\section{2.b. Kajian Pustaka}

Perancangan Sistem Informasi Pemesanan Katering Berbasis Web Pada Rumah Makan Tosuka Tangerang oleh Fatmawati

Informasi tentang Rumah Makan Tosuka masih belum banyak diketahui masyarakat khususnya yang sering menggunakan akses internet dan yang ingin melakukan pemesanan katering secara online. Sistem informasi pemesanan yang masih bersifat manual sehingga untuk mendapatkan informasinya masyarakat harus datang langsung ke Rumah Makan Tosuka. Dengan memanfaatkan teknologi internet informasi-informasi yang ada di Rumah Makan Tosuka bisa di akses dengan mudah dan pembeli dapat melakukan pemesanan katering lebih praktis. Berdasarkan hasil analisa pada penelitian ini penulis menggunakan metode pengembangan perangkat lunak menggunakan SDLC sedangkan tool yang digunakan berupa ERD (Entity Relationship Diagram) dan UML (United Modelling languange) sedangkan MySQL sebagai server database, Adobe Dreamweaver untuk aplikasi PHP. Dengan adanya aplikasi pemesanan katering ini dapat memberikan kemudahan pada pembeli dan meningkatkan pelayanan pada Rumah Makan Tosuka.

Sistem Informasi Pemesanan Pada Aditya Catering Berbasis Web oleh Ayu Susen Minarmas Ambarita, Heru Pramono

Aditya Catering adalah penyedia layanan makanan, terutama makanan dari berbagai makanan khas daerah di seluruh Indonesia. Pemesanan Katering makanasn masih sangat terbatas dalam ruang lingkup. Cara memesan masih banyak orang yang tidak tahu karena terbatasnya informasi yang diterima. Tujuan dari Sistem Informasi Pemesanan Catering ini adalah untuk memfasilitasi pemilik untuk memasarkan produk mereka dan mempermudah proses transaksi order online.
Alat yang digunakan untuk merancang sistem yaitu Flow of Document, Diagram Flow Diagram, Diagram Konteks, Entity relationship Diagram. Pemesanan Sistem adalah aplikasi berbasis web yang dirancang menggunakan MySql. Sementara perangkat lunak yang dipilih untuk merancang aplikasi ini adalah Notepad++ dengan WAMP. Dengan adanya sistem informasi pemesanan katering berbasis web ini dapat memberikan kemudahan kepada pelanggan untuk memesan katering secara cepat, pengolahan data makanan dan minuman bisa lebih baik dan akurat, sehingga pelanggan selalu mendapatkan informasi terbaru dari Aditya Catering. Di ambil dari http://mahasiswa.dinus.ac. id/docs/skripsi/jurnal/18792.pdf

\section{Analisa Dan Perancangan Sistem}

Metode untuk pengambangan perangkat lunak tentang katering ini menggunakan model waterfall sequential linear atau classic life cycle (Sukamto dan Shalahuddin dalam Yulia, 2017:28).

Berikut gambaran sistem rekasaya informasi :

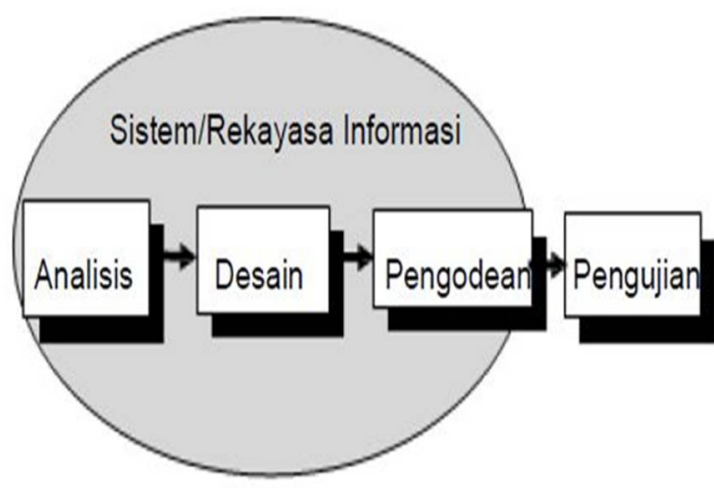

Sumber : Sukamto dan Shalahuddin dalam Yulia (2017:28)

Gambar 1 Rekayasa Informasi

Berikut adalah penjelasan dari tahapantahapan tersebut :

1. Analisis kebutuhan perangkat lunak Proses pengumpulan kebutuhan ditahap ini dilakukan secara intensif yang berguna untuk menspesifikasikan kebutuhan perangkat lunak yang dibutuhkan serta dapat dipahami oleh user.

2. Desain

Pada tahap ini lebih berfokus pada desain pembuatan program guna mentralesasikan agar dapat diimplementasikan ketahap selanjutnya.

3. Pembuatan kode program

Tahapan ini adalah pembuatan program komputer yang sesuai dengan desain yang telah dibuat. 
4. Pengujian

Proses pengujian berfokus pada segi logis dan fungsional dan memastikan semua bagian telah diuji serta keluaran yang dihasilkan apakah sesuai dengan yang diinginkan atau tidak

Pengumpulan data untuk menunjang pembuatan sistem dilakukan dengan cara observasi dan studi pustaka. Dengan data yang cukup diharapkan akan dapat membuat sistem yang baik tentang jasa katering.

Setelah data terkumpul dilakukan kegiatan analisa terhadap kebutuhan yang akan digunakan untuk menunjang sistem berbasis website yang hendak di buat. Adapun kebutuhannya yaitu terdiri atas kebutuhan fungsional dan kebutuhan nonfungsional.

1. Analisa Kebutuhan Fungsional

Dalam perancangan ini kebutuhan fungsional masing-masing pengguna antara lain:

a. Admin
1) Terdapat menu login.
2) Admin dapat menambah, mengubah dan menghapus data menu.
3) Admin dapat menambah, mengubah dan menghapus data user.
4) Admin dapat menambah, mengubah dan menghapus data kategori
5) Admin dapat melihat, memproses dan mencetak laporan pemesanan.
6) Terdapat menu logout

b. User/Pelanggan

1) Terdapat menu login.

2) User dapat melihat berbagai menu makanan.

3) User dapat melakukan pemesanan

4) User dapat melakukan konfirmasi

5) Terdapat menu log out

2. Analisa Kebutuhan Non Fungsional

Kebutuhan non fungsional dalam merancang website ini adalah sebagai berikut :

a. Operasional
1) Sistem
dapat diakses menggunakan web browser, seperti Google Chrome Mozilla Firefox atau lainnya.
2) Digunakan pada sistem operasi Microsoft Windows 7.
3) Spesifikasi komputer minimal Intel Pentium IV 1 Ghz.
4) Kebutuhan memori minimal $1 \mathrm{~GB}$ RAM.

b. Keamanan

\section{user.}

Dilengkapi dengan login admin, login

Password untuk admin dan user dienkripsi dengan md5.

c. Informasi

1) Menginformasikan apabila identitas user dan Password yang digunakan untuk login salah.

2) Menginformasikan apabila input yang dimasukan masih kosong.

3) Menginformasikan bahwa data yang telah di input berhasil disimpan, diubah dan dihapus.

4) Menginformasikan bahwa user dan Password sudah digunakan.

Selanjutnya di desain tampilan antarmuka agar pemakai sistem ini dengan mudah dapat berkomunikasi misalnya rancangan login, rancangan menu untuk Admin, rancangan untuk menambah menu katering dan rancangan-rancangan lainnya . Dibuat banyak rancangan-rancangan rencana tampilan program, pada penulisan ini hanya diberikan contoh sebagian rancangan yang sudah di buat, yaitu:

Rancangan Antar Muka Halaman Index Admin yang menampilan menu untuk Admin bekerja mengelola website.

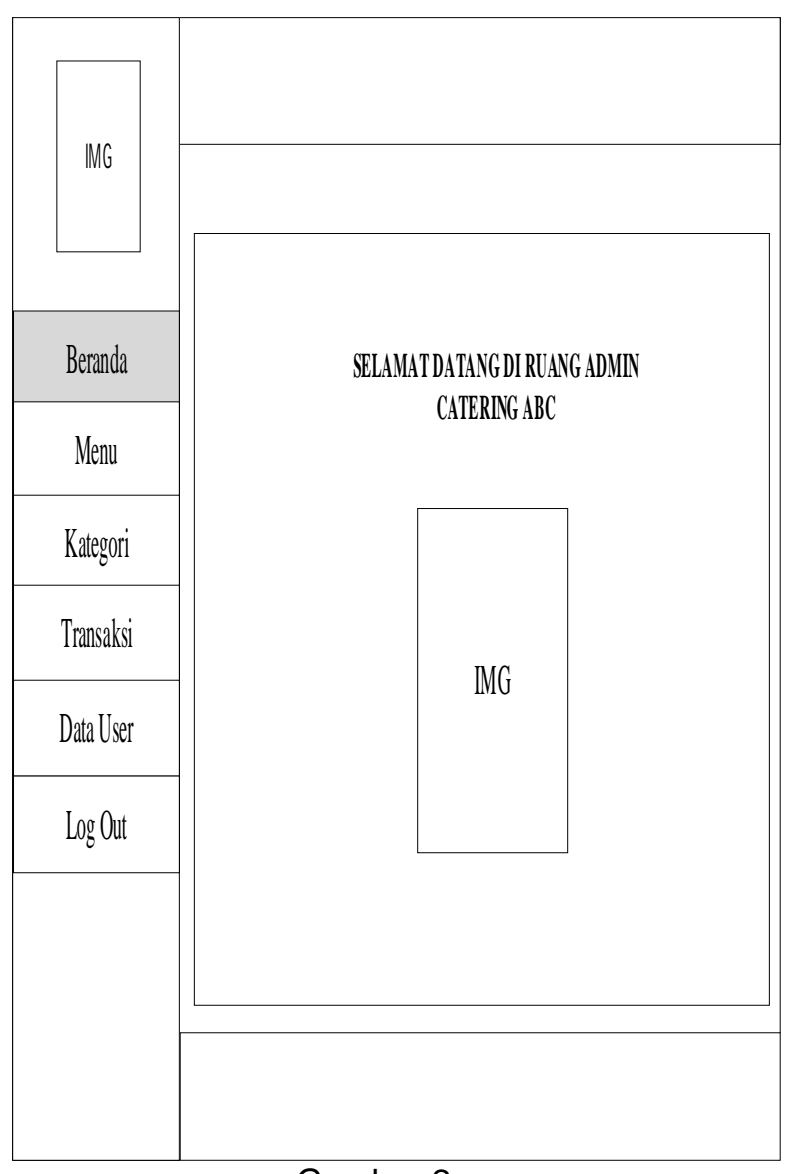

Gambar 2

Rancangan Antar Muka Halaman Index Admin 
Rancangan Antar Muka Halaman User atau pelanggan katering. Menu pilhan yang dapat diakses oleh user.

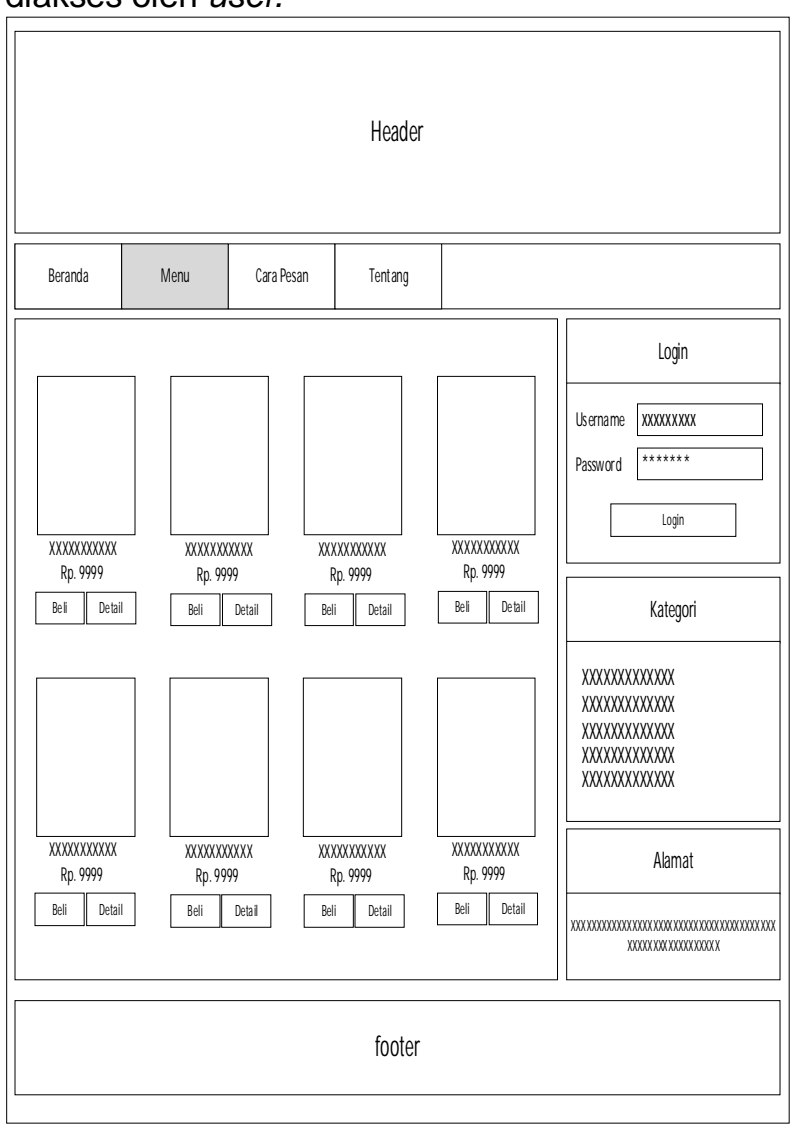

Gambar 3

Rancangan Antar Muka Halaman User Menu

Sebagian rancangan di atas dibuat untuk memudahkan pembuatan tampilan yang nyata yang dibuat dengan bahasa pemrograman. Dengan membuat rancangan yang terperinci dan lengkap sesuai kebutuhan di harapkan proses koding dalam mewujudkan aplikasi website bisa lebih cepat dan tepat.

Untuk menyimpan berbagai macam data diperlukan basisdata. Semua data dan transaksi yang akan dilakukan dibuat agar bisa disimpan, di edit dan di hapus. Berikut ini gambar LRS yang menunjukkan rancangan database yang dipakai untuk menyimpan data.

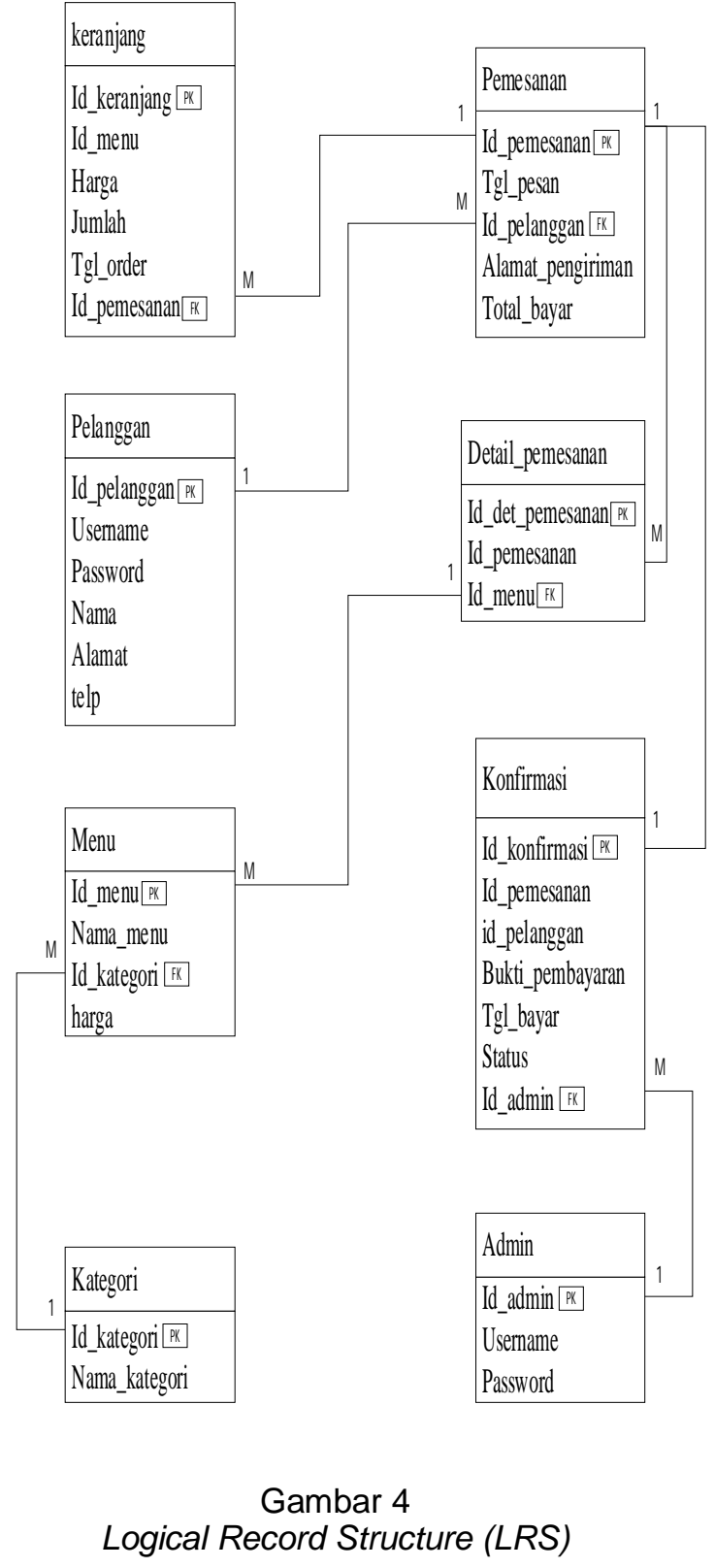

Dalam pembuatan rancangan dababase diawali dengan membuat ERD (Entity Relationship Diagram), kemudian LRS (Logical Record Structure), dan dilanjutkan membuat tabel-tabel basis data. Database dibuat dengan software MySql. Pembuatan database memerlukan ketelitian sehingga semua data yang harus disimpan harus dirancang dengan sebaik-baiknya. Dari gambar LRS tampak ada delapan tabel yang akan dibuat.

Untuk memudahkan jalannya website, menumenu yang ada dan berbagai aktivitas yang bisa dilakukan dalam sistem maka bisa dilakukan dengan melihat gambar navigasi berikut ini. 


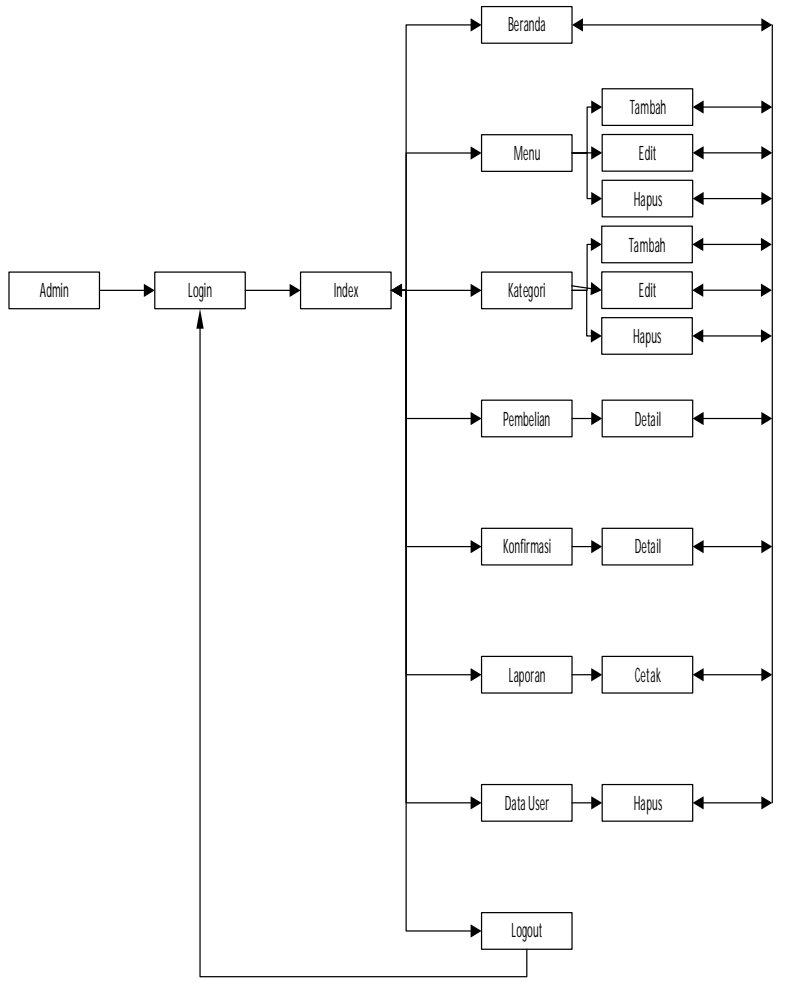

Gambar 5

Rancangan Struktur Navigasi Admin

Dari Rancangan tampilan, rancangan basis data dan rancangan navigasi selanjutnya dibuat antarmuka dengan kode bahasa pemrograman. Banyak antarmuka yang di buat sehingga admin atau pengguna aplikasi ini bisa dengan mudah melakukan transaksi. Berikut ini sebagian antarmuka yang sudah dibuat.

Halaman ini Admin dapat mengelola data menu di ruang Admin.

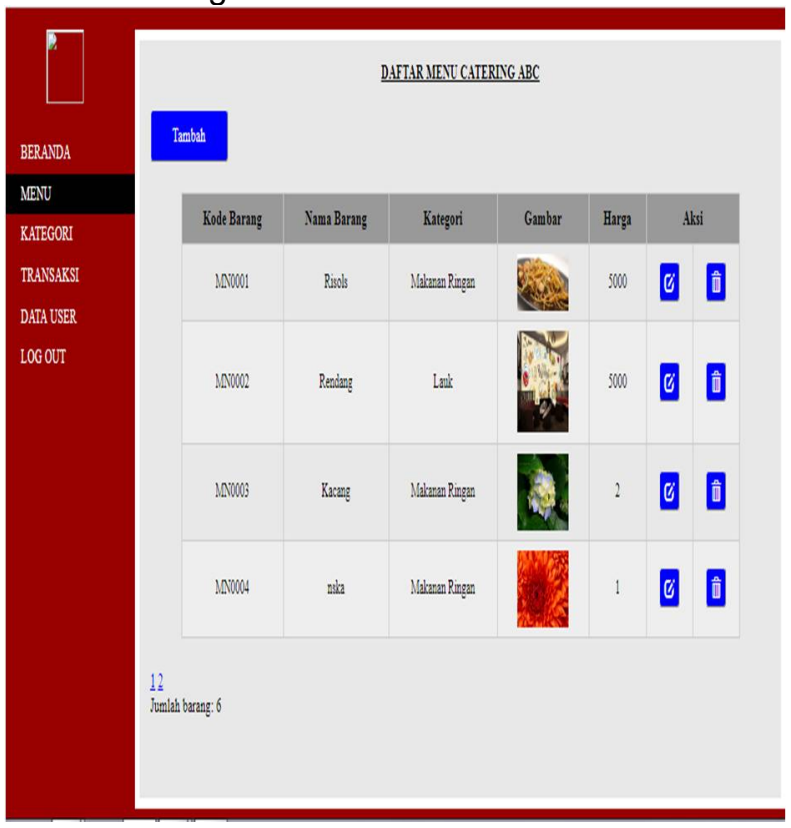

Gambar 6

Halaman Menu Admin

Halaman ini terdapat menu yang dapat dilihat dan dapat dibeli oleh user.

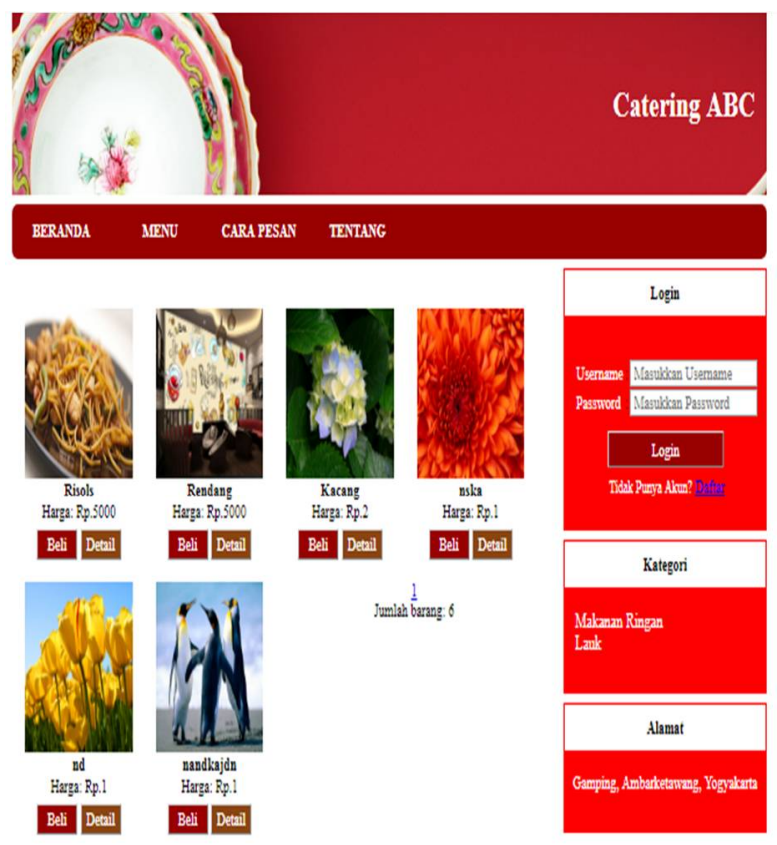

\section{Q2019 Catering ABC}

Gambar 7

Halaman Menu User

Antarmuka yang sudah jadi selanjutnya di tes dengan metode Blackbox sehingga bila ada kesalahan bisa segera di betulkan. Setiap langkah di uji coba sejak dari awal admin bekerja hingga pengguna dapat dilayani dengan baik dan lancar dengan sistem yang dibuat ini.

\section{Penutup}

Kesimpulan yang bisa diambil dari penuisan ini adalah:

1. Setiap usaha bisnis bisa ditunjang dengan berbagai teknologi sehingga bisnis bisa berjalan dengan baik. Misalnya bisnis katering di tunjang dengan teknologi informasi dalam hal ini dibuat sistem informasi berbasis website.

2. Pelayanan bisa dilakukan secara online, informasi bisa disampaikan selama 24 jam terus menerus, pemesan tidak harus ketemu atau datang langsung ke pihak katering.

3. Website pemesanan catering online ini dapat dengan mudah dipakai untuk pesan makanan dan dapat dijangkau secara 
luas dan cepat untuk semua kalangan masyarakat.

4. Proses transaksi untuk pembayaran pada aplikasi ini masih diakukan Via transfer Bank belum dibuat otomatis dalam website.

5. Diharapkan dengan adanya website ini bisa memudahkan usaha rumahan dalam mengelola catering secara online.

\section{DAFTAR PUSTAKA}

[1] Ambarita, Minarmas, Susen, Ayu dan Pramono Heru. 2016 .Sistem Informasi Pemesanan Pada Aditya Catering Berbasis Web,.Semarang. Udinus. Diambil dari

http://eprints.dinus.ac.id/19660/

[2] Andriani, Anik. 2016. Manajemen Basis Data Pemodelan, Perancangan, dan Penerapan. Yogyakarta: Deepublish.

[3] Dipraja, Samja. (2013). Panduan Praktis Membuat Website Gratis. Jakarta : Pustaka Makmur.

[4] Fatmawati. 2016. Perancangan Sistem Informasi Pemesanan Katering Berbasis Web Pada Rumah Makan Tosuka. Tangerang di ambil dari Jurnal Teknik Komputer AMIK BSI Vol. II, No. 2, Agustus $2016 . \quad$ https://ejournal. bsi.ac.id/ejurnal/index.php/jtk/article/downl oad/1609/1174

[5] Ferdika, Mikhael., dan Heri Kuswara. (2017). Sistem Informasi Penjualan Berbasis Web Pada PT Era Makmur Cahaya Damai Bekasi. Information System For Educators And Professionals, Vol 1 No 2, 175-188. Diambil dari http://ejournalbinainsani.ac.id/index.php/ ISBI/article/view/390. (18 Mei 2018)

[6] Fridayanthie, Eka Wida, dan Tias Mahdiati. (2016). Rancang Bangun Sistem Informasi Permintaan ATK Berbasis Intranet (Studi Kasus: Kejaksaan Negeri Rangkasbitung). Jurnal Khatulistiwa Informatika Volume IV No 2. Diambil dari http://ejournal.bsi.ac.id/ejurnal /index.php/khatulistiwa/article/.

Diakses tanggal 16 Agustus 2018.

[7] Hastanti, Puji, Rulia dkk. 2015 "Sistem Penjualan Berbasis Web (E-Commerce) Pada Tata Distro Kabupaten Pacitan".Jurnal Bianglala Informatika Vol. 3 No. 2, September 2015 - Diambil dari : https://ejournal.bsi.ac.id/

ejurnal/index.php/Bianglala/article/view/58 $1 / 472$

[8] Kusniawan, Andi dan Sardiarinto. 2016. Perancangan Website Jasa Desain
Interior Sebagai Media Pemasaran Studi Kasus CV Focalpoint Interior. Jurnal Evolusi. Vol 4 number 2, 2016. Diambil dari:http://ejournal.

bsi.ac.id/index.php/evolusi/article/view/69 4/50 (21 Mei 2018)

[9] Ningrum, Djustari Prehatin dan Ishak Kholil. 2015. Sistem Informasi Penjualan Drean Catcher Berbasis Web. Diambil dari:

https://www.slideshare.net/dejus93/jurnalsistem-informasi-penjualan-dreamcatcherberbasis-web. (22 Mei 2018)

[10] Pradiatiningtyas, Diah dan Suparwanto. 2017. E-Learning Sebagai Media Pembelajaran Berbasis Web Pada SMK N 4 Purworejo.

Indonesian Journal Of Network Security. Vol 7 number 2, 2018. Diambil dari: https://ijins.org/journal/index.php/ijins/articl e/view/1499/1460 (20 Mei 2018)

[11] Purwati, Nani dan Noor Hasan. 2016. Perancangan Sistem Informasi Administrasi Tamu Hotel (Studi Kasus Pada Hotel Ganesha Purworejo). Diambil dari Journal Speed - Sentra Penelitian Engineering dan Edukasi - Volume 8 No 1 http://ijns.org/ journal/index.php/speed/article/view/1395

[12] Sadeli, Muhammad. 2013. Toko Baju Online dengan PHP dan MySQL. Palembang : MaxiKom.

[13] Sibero, F.K Alexander . 2014. Web Programming Power Pack. Yogyakarta: Mediakom.

[14] Sukamto, Rosa A., dan M. Shalahuddin. 2014. Rekayasa Perangkat Lunak Testruktur dan Berbasis Objek. Bandung: Informatika Bandung.

[15] Supriyanta dan Khoirun Nisa. 2015. Perancangan Website Desa Wisata Karangrejo Sebagai Media Informasi Dan Promosi. Jurnal Bianglala Informatika. Vol 3 number 1, Maret 2015. Diambil dari http://ejournal.bsi.ac.id/jurnal/index.php/ Bianglala/article/view/575/466. (20 Mei 2018)

[16] Wibisono, Guntur dan Wahyu Eko Susanto. 2015. Perancangan Website Sebagai Media Informasi dan Promosi Batik Khas Kabupaten Kulonprogo. Jurnal Evolusi Vol 3 no 2, 2015. Diambil dari: http://ejournal.bsi.ac.id/ejurnal/ index.php/evolusi/article/view/630/521.(21 Mei 2018)

[17] Winarno, Edy dan Ali Zaki. 2014. Pemrograman Web Berbasis HTML 5, PHP \& Javascript. Jakarta: Elex Media Komputindo. 